\title{
El AMOR EN LOS TIEMPOS DE LA MÁQUINA: E.T.A. Hoffmann, Adolfo Bioy Casares y Cristina Civale*
}

\author{
Sophie von Werder ${ }^{* *}$
}

\begin{abstract}
Resumen
En este artículo realizo un estudio comparado de tres relatos: El hombre de la arena (1816/17), del escritor alemán E.T.A. Hoffmann; La invención de Morel (1940), de Adolfo Bioy Casares; y "Perra virtual" (1998), de Cristina Civale, escritores argentinos los dos últimos.

La influencia de la tecnología y su relación con el amor es el leitmotiv de estas narraciones. Los protagonistas se enamoran, pero su amor es intervenido y mediado por la tecnología de la respectiva época: se enamoran de una máquina, de un espejismo o de una identidad virtual. Se analiza la profunda relación de la literatura con otros medios.
\end{abstract}

Palabras clave: Literatura comparada, intermedialidad, tecnología, amor, cuerpo.

\section{Love In the TIME Of MACHINES: E.T.A. HofFMANN, Adolfo Bioy Casares y Cristina Civale}

\begin{abstract}
In this article, I conduct a comparative study of three stories: The Sandman (1816/17), Invention of Morel (1940), and "Perra Virtual" (1998). The former written by German author E.T.A. Hoffmann, the latter two by Argentineans Adolfo Bioy Casares and Cristina Civale. The influence of technology and its relationship to love is the leitmotiv of these narratives. The main characters fall in love, but their love is disrupted and mediated by the technology of their respective eras: they fall in love with a machine, a mirage, or a virtual identity. I analyze the profound relationship of literature to other media.
\end{abstract}

Key words: Comparative literature, intermediality, technology, love, body.

Recibido: 15-12-2015

Aceptado: 16-05-2016

* Este artículo se inscribe en el Proyecto de Investigación Literatura e hiperrealidad: un estudio comparado, Etapa III, realizado con el apoyo del Centro de Investigaciones y Extensión de la Facultad de Comunicaciones de la Universidad de Antioquia, adscrito al Grupo de Estudios Literarios (GEL). Forma parte de la Estrategia de Sostenibilidad del grupo GEL de 2014-2015.

** Alemana. Doctora en Literatura Latinoamericana de la Universidad de Concepción. Académica de la Universidad de Antioquia. Coordinadora del Grupo de Estudios Literarios (GEL), Departamento de Lingüística y Literatura, Facultad de Comunicaciones, Medellín, Colombia. svonwerder@gmail.com 


\section{Introducción}

En el presente trabajo se revisa la relación entre amor y tecnología en tres obras y momentos de escritura distintos, mediante un estudio comparado de: El hombre de la arena (1816/17), de Ernst Theodor Amadeus (E.T.A.) Hoffmann, escritor alemán; La invención de Morel (1940), de Adolfo Bioy Casares; y "Perra virtual" (1998), de Cristina Civale, estos dos últimos, escritores argentinos.

Los protagonistas de los tres relatos se enamoran de un simulacro generado por medio de las tecnologías innovadoras de la respectiva época: un medio mecánico en el caso de Hoffmann, un medio que permite la grabación y reproducción en el caso de Bioy, y la virtualidad en el caso de Civale. Hoffmann y Bioy, además, van más allá de las posibilidades reales de su respectivo tiempo y escriben novelas de ciencia ficción.

Los relatos se pueden leer como metáforas del amor, de un amor que se basa en el engaño y la ilusión proyectada en el amado y, en consecuencia, tiene un final desafortunado. En la obra de Civale, el relato termina con la humillación y el desconsuelo del personaje central; en Hoffmann y Bioy, incluso con su suicidio. Las tecnologías seducen al hombre, sin embargo, lo confunden y lo pueden destruir.

En la siguiente investigación se realiza, en primer lugar, un análisis de cada relato en particular, para luego llevar a cabo un estudio comparativo que permita establecer sus semejanzas y diferencias. Es este el propósito del artículo, para lo cual se presentan dichas narraciones de acuerdo con el orden cronológico de su publicación.

\section{El narcisista y el Otro en El hombre de la arena de E.T.A. Hoffmann}

El hombre de la arena es una novela corta que forma parte de los Cuadros nocturnos (1816/17). En este relato, el protagonista -Natanael- se enamora de Olimpia, sin saber que ella es una autómata o robot, la imitación muy avanzada de una mujer que, a pesar de cierta rigidez en los movimientos y la mirada fija, pasa prácticamente desapercibida. Al incorporar a la autómata en su narración, Hoffmann no sólo vuelve los ojos al amor y a la relación entre hombre y mujer, sino que escribe ciencia ficción y observa la conexión que se establece entre el hombre y las máquinas. 
Vamos a dejar de lado en este estudio otros aspectos, como los recuerdos de la infancia de Natanael, el encuentro con dos personajes siniestros, o la muerte del padre en extrañas circunstancias, los que si bien son importantes en la obra, son poco relevantes para el presente análisis.

El avance tecnológico a Natanael le fascina, pero su desgracia comienza justamente con la compra de un catalejo de bolsillo que le permite agudizar su percepción visual. Natanael está comprometido con Clara; sin embargo, se enamora de Olimpia cuando la observa a través del catalejo. Cuando se da cuenta de que ella es una autómata sin vida, pierde la razón y trata de ahorcar al inventor de la muñeca. Más adelante, también a través del catalejo, ve a Clara, y, en un segundo ataque de locura, intenta matarla. Finalmente, se suicida.

El hombre de la arena es un texto a partir del cual se han elaborado interpretaciones muy diversas, entre las que destacan las psicoanalíticas y las sociológicas. Ejemplo de esto es que la novela ha sido leída por algunos como el estudio de un caso psicopatológico (Freud, 1919; Mahlendorf, 1980); otros observan que la obra contrapone las perspectivas de la Ilustración y del Romanticismo (Aichinger, 1976; Maldonado 2001); y también -desde una lectura poetológica-, se ha señalado que la novela remite a un proceso de producción textual (Sommerhage, 1978).

El presente trabajo propone leer este relato como una sátira de la relación amorosa; Natanael se enamora, única y exclusivamente, porque inconscientemente proyecta sus deseos y su propio ser en Olimpia.

Olimpia es una muñeca, pero el enamorado la llena de vida: "Fría como el hierro era la mano de Olimpia, él se sintió sacudido por un frío terrorífico y mortal, miró fijamente a Olimpia a los ojos, que irradiaban a su encuentro puro amor y melancolía, y en ese instante fue como si la fría mano comenzara a latir pulso y las corrientes de sangre ardieran al rojo vivo" (Hoffmann, El hombre de la arena 27).

El protagonista del relato incluso se convence de que Olimpia lo escucha, y cree percibir entre los dos una profunda unión a nivel espiritual:

Sólo tú, tú eres la única que me comprende enteramente. Se estremecía con un profundo encanto cuando consideraba qué armonía maravillosa se revelaba a diario entre su 
espíritu y el de Olimpia, pues sentía como si Olimpia hubiera hablado a través de sus obras, a través de su talento poético en general, desde lo profundo de su ser, es más, como si la voz de Olimpia hubiera sonado desde su interior. (30)

Natanael es un personaje narcisista que quiere ser comprendido (Grobe 45; Pearson 20-21). No le interesa conocer al otro, y en el fondo es intolerante a toda alteridad e incapaz para el amor hacia una persona real. Por eso no le preocupa que Olimpia casi no diga nada: "Habla poco, es verdad, pero esas pocas palabras aparecen como verdaderos jeroglíficos de un mundo interior repleto de amor y supremo conocimiento de la vida espiritual que contempla el eterno paraíso" (Hoffmann, El hombre de la arena 29$)$.

Con Clara, en cambio, los problemas se dan justamente porque ella piensa y no siempre está de acuerdo. Irónicamente, cuando a Clara no le gusta un cuento que Natanael escribió, él le dice: “¡Ah, tú... maldita autómata insensible!" (20). Fortin (2004) observa en la obra una verdadera confusión entre lo orgánico y lo mecánico, porque un cuerpo inanimado parece cobrar vida, mientras las personas se portan o se tratan como máquinas (266).

Sin embargo, la tecnología en El hombre de la arena se revela como peligrosa. El hombre puede caer en la locura, convertirse en asesino o en suicida. Maldonado señala que en el universo narcisista de Natanael, su propio yo se confunde con el entorno, se autoidentifica con el Otro. Por esta razón, "la destrucción de Olimpia trae consigo la destrucción de Natanael" (85).

Por otro lado, en la obra de Hoffmann, indudablemente subyace una crítica a la sociedad patriarcal, en cuanto podemos constatar que una autómata que no habla, no contradice ni tiene opinión, es aceptada en la sociedad. Sus muy limitadas y estereotipadas expresiones se corresponden con el rol social de la mujer de la época; en cambio, el hombre se presenta como "un ser controlador, débil, y a veces loco" (Scullion y Treby 301).

Hoffmann vuelve a usar un tono irónico cuando el narrador nos informa que los enamorados, al salir a la luz la verdadera naturaleza de Olimpia, ponen a prueba a sus novias: 
Y para estar totalmente convencido de que no se amaba a una muñeca de madera, fue exigido por numerosos amantes que la amada cantara y bailara fuera del compás, que durante los recitados ella bordara y tejiera, que jugara con su mascotita pero, sobre todo, que no sólo escuchara sino que a veces también hablara, de modo que sus palabras supusieran la capacidad de pensar y sentir. (33)

El hombre de la arena, aparte de ser una crítica de la sociedad patriarcal de su época, es una parodia del enamoramiento y de la gran capacidad para la proyección que desarrolla el enamorado. Este se siente reflejado -y también comprendido- por alguien que no existe. El amor es, entonces, una falacia.

\section{Máquina, muerte y amor eterno en La invención de Morel de Bioy Casares}

El segundo texto que forma parte de la comparación es La invención de Morel (1940), de Adolfo Bioy Casares, que en su línea argumental versa sobre un perseguido por la justicia que se refugia en una isla abandonada y se va enamorando de una proyección, de un simulacro de mujer. El personaje central del relato es a la vez su narrador; un narrador poco confiable en este caso, que transmite la sensación de irrealidad y de duda, porque está enfermo y parece trastornado, paranoico a veces, y exaltado otras. Habla de dolores y ataques de fiebre, se le borra el tiempo medible y verificable (Bioy Casares 59), no distingue claramente entre el sueño y la vigilia, y la luna y el sol se le aparecen dobles (64). Al depender de este narrador, el lector mismo percibe lo que será un tema central de la novela: lo inestable de la noción de la realidad y, más específicamente, la rivalidad entre realidad y simulacro; la dificultad para distinguir entre lo uno y lo otro.

Al fugitivo, de pronto se le aparecen unas personas, "bruscamente presentes, como si no hubieran llegado, como si hubieran aparecido nada más que en mi vista o imaginación" (26). Entre estos intrusos está Faustine, una mujer que va todas las tardes a las rocas a mirar la puesta del sol. El protagonista del relato se enamora de ella y la espera en las tardes para observarla desde un escondite. Cuando finalmente toma la decisión de hablarle, ella no responde: "No fue como si no me hubiera oído, como si 
no me hubiera visto; fue como si los oídos que tenía no sirvieran para oír, como si los ojos no sirvieran para ver" (32). Más adelante, el protagonista incluso se tira de rodillas y le grita que la quiere, pero ella vuelve a seguir adelante como si no lo percibiera (70).

Poco a poco, el fugitivo se entera de que las personas que ve están muertas, que lo que percibe son proyecciones grabadas con unas máquinas inventadas por Morel, quien forma parte del grupo. ${ }^{1}$ Los veraneantes son apariencias muy completas y perfectas; las máquinas de Morel cuentan con receptores visuales, auditivos, olfativos y táctiles, y logran una reproducción sinestética e idéntica de las personas.

La grabación que el fugitivo ve se realizó durante una semana, causó la muerte de las personas grabadas y ahora se proyecta indefinidamente: “Como la semana se repite a lo largo del año, se ven esos soles y lunas no coincidentes (y también los moradores con frío en días de calor; bañándose en aguas sucias [...])" (116).

Al final del relato, el fugitivo utiliza la proyección original como trasfondo y se graba al lado de Faustine.

La novela de Bioy, al igual que la de Hoffmann, ha sido ampliamente estudiada y elogiada. Borges, en su famoso prólogo afirma: "no me parece una imprecisión o hipérbole calificarla de perfecta" (19), y subraya la calidad estética de la obra, la cual considera como autorreferente y opuesta a la novela sicológica, idea que es acogida por MacAdam (1977), quien interpreta la novela como una metarreflexión sobre la creación literaria. Bautista (2009), no obstante, cuestiona estos planteamientos, señalando los elementos alegóricos y psicológicos de la obra.

Sin el ánimo de presentar aquí todas las perspectivas que se han desarrollado, hay que mencionar a Seegert (2012), quien establece una relación entre la máquina de Morel y el eterno retorno nietzscheano. Aparte de eso, Seegert observa que el fugitivo pretende ser autor y artista, crea un mundo, y de esta manera supera a Morel, quien solamente se plantea reproducir un mundo existente. Ordiz Alonso-Collada, por otro lado, resalta la afinidad entre el concepto freudiano de lo ominoso como mezcla de lo familiar y lo extraño, y la ambivalencia de los veraneantes

1 De acuerdo a Agudelo (22-23), en un sentido amplio, esta representación verbal de un objeto visual se relacionaría con la dimensión semiótica de la écfrasis literaria. 
como humanos, que "al mismo tiempo, son representantes de la otredad, de lo incomprensible y de la muerte" (13).

Esta idea nos sirve de punto de partida, porque la otredad aquí se relaciona con la muerte y con el anhelo de eternidad de los personajes que recorre la novela. El narrador está convencido de que "perdemos la inmortalidad porque la resistencia a la muerte no ha evolucionado" (Bioy Casares 16). Morel reflexiona en varias ocasiones acerca de la inmortalidad $(53,77)$, y reconoce que el deseo de eternizarse fue un importante móvil a la hora de inventar la máquina $(76,77,82)$. El narrador, a su vez, sospecha que Morel también puede estar enamorado de Faustine y que "tramó en la semana, la muerte de todos sus amigos, para lograr la inmortalidad con Faustine" (118). Más adelante, él mismo se graba para eternizarse al lado de Faustine, a pesar de que está consciente de que ese acto le va a costar la vida. La muerte incluso se presenta como una oportunidad más que un sacrificio; el protagonista opina que "la verdadera ventaja de mi solución es que hace de la muerte el requisito y la garantía de la eterna contemplación de Faustine" (119).

Observamos cómo en la novela de Bioy, la tecnología -y también el amor- establecen relaciones complejas tanto con la muerte como con el deseo de eternidad. El enamorado anhela la eternidad al lado de la mujer amada; un deseo paradójico porque eternidad y vida son incompatibles. Aquí la decisión es tajante: para eternizarse, hay que grabarse y morir.

Paz Soldán (2007) observa que la novela "relaciona los medios de masas con la idea del archivo, y a ambos con la muerte y el más allá". Hay aquí un "triunfo final de la tecnología" $(766,767)$, porque el protagonista, enamorado de una mujer muerta y seducido por la tecnología, voluntariamente entrega su vida. La reproducción a través de un invento mecánico, amenaza con suplantar todos los originales, los que parece atraer, succionar $y$, finalmente, absorber.

Las imágenes en la obra de Bioy comienzan entonces a rivalizar con la realidad, desestabilizándola. En este sentido, la novela anticipa ideas que Jean Baudrillard va a desarrollar en los años 70. El sociólogo francés observa que en la era del consumo y de los medios audiovisuales, la producción y difusión de imágenes se vuelven fundamentales. Las imágenes o simulacros comienzan a invadir la realidad, la remplazan hasta expulsarla, y crean la llamada hiperrealidad: "Hoy, todo el 
sistema oscila en la indeterminación, toda realidad es absorbida por la hiperrealidad [...] de la simulación. Es un principio de simulación que nos rige en lo sucesivo, en lugar del antiguo principio de realidad" (El intercambio simbólico y la muerte 6). De hecho, el protagonista de $\mathrm{La}$ invención de Morel no sólo no es capaz de distinguir cuál de las lunas que ve corresponde al simulacro y cuál a la realidad, sino que también la duda se extiende a su propia existencia; este narrador sin nombre no sabe si está soñando o si está muerto. Cuando trata de explicarse por qué Faustine parece no percibirlo, evalúa la posibilidad de que a lo mejor "el aire pervertido de los bajos y una deficiente alimentación me hayan vuelto invisible" (61), o en el caso de que los otros estuvieran muertos, él podría ser "otro muerto, de otra casta, en un momento diferente de su metamorfosis" (62).

Como en esta narración la realidad es un concepto dudoso, la duda también afecta al amor. Por un lado, se desarrollan varios clichés del amor romántico como el amor eterno, el deseo y su imposibilidad (López Pellisa 74), o el morir por amor (Bautista 409). Sin embargo, en La invención de Morel, al igual que en El hombre de la arena, el amor es un imposible. Ordiz Alonso-Collada (2012) observa que los veraneantes son seres "presentes y a la vez inalcanzables" (11). De acuerdo con Cavallari (1999), la ausencia del cuerpo femenino sería una forma del "exilio de lo Otro" (262), o "exilio erótico" $(268,269)$. Por su parte, Giraldo (2005) observa que el relato de Bioy responde a la pregunta por la dinámica amorosa, y resume que "sólo podemos amar imágenes" (62).

Lo cierto es que el protagonista, cuando se entera de que la amada es un simulacro, se acostumbra a verla "sin emoción, como a un simple objeto" (Bioy Casares 93). Sin embargo, de las imágenes grabadas que pertenecen a diferentes tiempos, quiere hacer un collage para lograr el efecto y la apariencia de un amor mutuo y una relación íntima, desafiando o simplemente desatendiendo la fundamental diferencia entre realidad y simulacro. Si el amor es realmente respondido o no pasa a segundo plano siempre que la apariencia se logre. Con ello, la instancia que podría evaluar la "obra", o sea, la relación entre Faustine y el personaje narrador, no sería el artista ni el enamorado, sino un tercero. Se renuncia a la realidad a favor del simulacro.

Sin embargo, persiste en el protagonista una distancia y un contraste grande entre la imposibilidad de establecer cualquier tipo de contacto o 
comunicación con la mujer amada, y el deseo de lograr una fusión a nivel espiritual cuando en el último párrafo le suplica al lector que lo haga "entrar en el cielo de la conciencia de Faustine" (123).

\section{Amor y pantalla en "Perra virtual" de Cristina Civale}

El tercer texto que entra en este estudio comparado es "Perra virtual" (1998), de Cristina Civale, un relato que forma parte de un libro de cuentos con el mismo título. La protagonista, de nombre Luz, es una prostituta que consigue a sus clientes en Internet, y en buena medida también los atiende a través de este medio.

La obra de Civale ha sido muy poco estudiada; sin embargo, vale mencionar dos trabajos que enfocan la construcción cultural de lo femenino en diferentes cuentos de la autora. Pascale (2002) ve en el título del relato una alusión a un animal que se defiende, que muestra los dientes, que es independiente y fuerte (511), mientras Martínez Díaz (2009), muy al contrario, observa que el lenguaje aquí empleado "nos sitúa inmediatamente dentro del discurso patriarcal" (40).

En realidad, se pueden desarrollar diferentes puntos de vista, porque Luz es un personaje paradójico. Por un lado, ella vive de la relación sexual, pero le gusta lo limpio, incorpóreo, aséptico. Los hombres no solo se contactan por Internet, también tienen que realizar el pago por ese medio, ingresando el número de su tarjeta de crédito, porque ella no quiere recibir el dinero de sus manos, pues "la exasperaba el contacto con esos papeles sucios y manoseados" (Civale 5).

Por otro lado, Luz es muy independiente y autónoma, y rompe con el esquema de mujer pudorosa o pasiva. Ser prostituta aquí no se corresponde con una necesidad, sino con una opción por la que ella conscientemente decidió. Luz entiende el sexo como parte del sistema capitalista, como una transacción económica como cualquier otra. En realidad, como en buena medida evita el contacto físico con los clientes, logra atenderlos sin casi involucrarse con ellos. En este sentido, su posición frente al hombre es fuerte: él le tiene que pagar a ella, pero ella le ofrece una suerte de sucedáneo y evita entregar su cuerpo.

Sin embargo, al utilizar el chat, Luz se enamora de una persona ficticia, producto de una mentira. Puede considerarse otra paradoja en una mujer 
madura, experta en las relaciones íntimas, la manera adolescente de enamorarse apenas lee un nombre rimbombante: el día que le llega un chat de Aquiles García de Andina, Luz sabe "que de él iba a enamorarse, del nombre, y de quien así se llamase". Y la llegada de Aquiles García de Andina a su computadora y a su vida "la trastornaron de un modo impredecible" (Civale 6-7). Ella guarda sus chats, los imprime, y "dedica muchas horas de sus días a leerlos con devoción, buscando cada vez un nuevo significado y sobre todo, alguna velada declaración de amor" (7). Sin embargo, cuando acude a la primera cita con García de Andina, le informan que él no vive en esa dirección, ni nunca ha vivido. "Luz no contaba con eso y se desmoronó. Pero su amor, arbitrario y ahora nada fugaz, no murió en ese instante. Se agrandó y cobró el tamaño de una obsesión" (8).

Cuando vuelven a acordar un encuentro, la esperan cinco muchachos de quince años que le explican: "Nosotros somos Aquiles García de Andina" (9). Esta vez, Luz entrega su cuerpo, paga por su error y hace el amor con todos. Pero al salir del apartamento, "unas carcajadas de hiena lastimaron sus oídos y cuando los chicos terminaron de reír hasta quedar ahogados, tirados sobre el piso, Luz ya estaba en su casa desarmando el monitor de su computadora, desnuda y abatida, buscando allí dentro a su hombre perdido. En alguna parte tendría que estar Aquiles García de Andina" (9).

\section{A modo de conclusión}

Se va a dar paso a la comparación de las tres obras presentadas, en las que podrán observarse importantes variaciones en el tratamiento de la temática según la época a la que pertenece la respectiva obra. De acuerdo con las innovaciones tecnológicas del momento, varía el impacto que en los respectivos mundos narrados tienen los medios sobre la relación amorosa.

El hombre de la arena y La invención de Morel, a diferencia de "Perra virtual", son relatos de ciencia ficción; a pesar de ello, no dejan de inspirarse en las tecnologías reales y novedosas de su respectivo tiempo.

E.T.A. Hoffmann escribe su obra en la era industrial, cuando los medios mecánicos revolucionan el mundo. Se inventan máquinas que realizan movimientos rígidos y rítmicos, básicamente al servicio de los 
procesos de producción. En ese contexto, Hoffmann ingenia un cuerpo femenino mecanizado.

La obra de Bioy, en cambio, está influenciada por los medios audiovisuales, principalmente por el cine, en razón a que, cuando concibió la novela, era el medio más novedoso. Bioy acoge la idea de la grabación y la reproducción de estímulos visuales y auditivos, y la perfecciona agregándole elementos táctiles y olfativos.

Civale, por su parte, escribe su cuento en la era de la información, y realiza una evaluación estética acerca del impacto de los medios digitales y de la virtualidad en la relación humana. Los nuevos medios son interactivos. Mientras en los relatos de Hoffmann y Bioy, el enamorado básicamente contempla y adora al objeto de su deseo, pero la tecnología lo aísla y lo incomunica, en la narración de Civale, lo que provoca el enamoramiento es justamente la interacción con el otro.

Sin embargo, observamos que en los tres relatos los protagonistas se enamoran de alguien que no existe; su enamoramiento es ilusorio. El personaje central de El hombre de la arena se enamora de una robot, el de La Invención de Morel de una muerta o un espejismo, y, finalmente, la protagonista de "Perra virtual" se va enamorando de un personaje inventado, de una ficción.

Por otro lado, todos los relatos coinciden en que el enamorado contribuye a esta situación con el autoengaño, al proyectar sus necesidades en el objeto del deseo. El hecho de que estos personajes no se enamoren de una mujer o de un hombre real sugiere que esta podría ser la esencia en todo enamoramiento: en el fondo no estaría dirigido hacia un Otro, sino hacia la percepción que se quiera o necesite tener de él.

Como en los relatos de Hoffmann y Bioy, las mujeres amadas no se pueden comunicar ni tienen autonomía para reaccionar frente a una situación. Ellas se limitan a ser objetos. Y dado que no actúan por cuenta propia ni pueden contradecir, se prestan especialmente para que un enamorado se proyecte en ellas, tendencia que se puede acentuar cuando el hombre tiene una personalidad narcisista.

Finalmente, en los tres relatos, las tecnologías seducen al hombre pero lo desorientan y pueden poner en peligro su salud mental y hasta su vida. Como ya observamos, en la obra de Hoffmann el protagonista 
pierde la razón y se suicida. También el personaje central de la novela de Bioy se quita la vida. En "Perra virtual", el enamoramiento y el engaño conducen a la humillación y a la desesperación de la protagonista.

En beneficio de la discusión, el cuento de Civale propone una reflexión acerca de los medios digitales y su relación con el espacio, el cuerpo y la relación íntima. Los nuevos medios relativizan y hasta logran abolir tiempo, espacio y cuerpo, tendencia que se inició en los años 80 con la televisión por cable y se ha profundizado desde la llegada de internet. Cada vez más se sustituye la presencia por la telepresencia, y el hombre comienza a prescindir del cuerpo para visitar lugares lejanos o encontrarse con los demás.

En las obras analizadas, el cuerpo va desapareciendo de manera progresiva. En un primer momento, contamos aún con la reproducción material de un cuerpo de mujer; luego aparece la proyección, el simulacro y comienzan a desaparecer los cuerpos. Lo que queda es apenas el reflejo de una entidad que en algún momento existió.

Finalmente, en nuestra época, internet nos independiza de nuestro cuerpo físico; además, como medio interactivo, invita al usuario a la autoconstrucción, a escoger libremente, si se quiere, características físicas, sexo, o edad; y en las relaciones humanas aparecen fenómenos tan novedosos como paradójicos: se conjugan la intimidad con el anonimato, o el encuentro sexual con el estado incorpóreo. 


\section{Referencias Bibliográficas}

Agudelo Rendón, P. Cuadros de ficción: Artes visuales y écfrasis literaria en Pedro Gómez Valderrama. Medellín: La Carreta, 2015.

Aichinger, I. E.T.A. Hoffmanns Novelle Der Sandmann und die Interpretation Siegmund Freud. Deutsche Philologie 95 (1976): 113-132.

Baudrillard, Jean. (1976). L'échange symbolique et la mort. Paris: Gallimard, 1976.

. El intercambio simbólico y la muerte. Trad. Carmen Rada. Caracas: Monte Ávila Editores, 1993.

Bautista, D. "Fantastic Psychology and Mechanical Allegory in The invention of Morel". Extrapolation 50.3 (2009): 400416.

Bioy Casares, A. La invención de Morel. Madrid: Alianza, 2012.

Borges, J.L. "Prólogo a 'La invención de Morel'". Decursos:revista de ciencias sociales 4.7 (Agosto 1999): 17-19.

Cavallari, H. M. "El exilio sin fin: de Subiela a Bioy Casares". Alba de América 15.28-29 (Julio 1999): 262-271.

Civale, Cristina. Perra virtual, Buenos Aires: Planeta, 1998.

Fortin, J. "Brides of the fantastic: Gautier's Le pied de momie and Hoffmann's Der Sandmann". Comparative Literature Studies 41.2 (2004): 257-275.

Freud, Sigmund. "Das Unheimliche". S. Freud, Psychologische Schriften Studienausgabe 4 (1970): 241-274. Versión en español Damián Toro.Web. 20 Febrero 2015.

Giraldo, E. A. "La invención de Morel; una fábula sobre el mito fotográfico". Revista Universidad de Antioquia 282 (Oct.-Dic. 2005): 60-67.

Grobe, Horst. Textanalyse und Interpretation zu E.T.A. Hoffmann; Der Sandmann. Hollfeld: Bange, 2000.

Hoffmann, E.T.A. Der Sandmann. Stuttgart: Reclam, 1986. 
Hoffmann, E.T.A. El hombre de la arena. Trad. por Nicolás Gelormini. Madrid: Libros del Zorro, 2006.

López Pelliza, T. "Virtualidades distópicas en la ficción analógica: La invención de Morel, de Adolfo Bioy Casares". Iberoamericana 78. 238-239 (Enero-Junio 2012): 73-89.

MacAdam, A. Modern Latin American Narratives: Dreams of Reason. Chicago and London: The University of Chicago Press, 1977.

Mahlendorf, U. "E.T.A. Hoffmanns Sandmann: die fiktive PsychoBiographie eines romantischen Dichters". Psychoanalyse und das Unheimliche. Ed. C. Kahane. Bonn: Bouvier Verlag H. Grundmann, 1981. 200-227.

Maldonado Alemán, A. "Der Sandmann de E.T.A. Hoffmann o la temporalidad de la interpretación literaria". Philologia Hispalensis 15.2 (2001): 69-88.

Martínez Díaz, M. "Seducción, disciplina y alteridad en Chica fácil de Cristina Civale". Filología y Lingüística 1.33 (2009): 39-51.

Ordiz Alonso-Collada, I. "El modo gótico en La invención de Morel de Adolfo Bioy Casares". Estudios Humanísticos. Filología 34 (2012): 133-145.

Pascale, E. "Cuerpos ausentes, cuerpos heridos: las mujeres en la narrativa de Cristina Civale". La literatura hispanoamericana con los cinco sentidos. Ed. Eva Valárce. Coruña: Universidad de Coruña, 2002. 507-514.

Paz Soldán, Edmundo. "La imagen fotográfica, entre el aura y el cuestionamiento de la identidad: Una lectura de La Paraguaya de Augusto Céspedes y La invención de Morel de Adolfo Bioy Casares". Revista Iberoamericana 73.221 (Octubre-Diciembre 2007): 759-770.

Pearson, J. "Total narcissism and the uncanny. A new interpretation of E.T.A. Hoffmann's The Sandman". ANGELAKI 18.2 (Junio 2013): 17-27. 
Seegert, A. "The Mistress of Sp[1]ices: Technovirtual Liaisons in Adolfo Bioy Casares's The invention of Morel". Journal of the Fantastic in the Arts 23.2 (2012): 197-214.

Scullion, V y Treby, M. "Sexual politics in the narratives of E.T.A. Hoffmann". Journal of Gender Studies 22.3 (2013): 297308.

Sommerhage, C. "Hoffmanns Erzähler. Über Poetik und Psychologie in E.T.A. Hoffmanns Nachtstück Der Sandmann". ZfdPH 106 (1987): 513-534. 